\title{
Barriers to disaster preparedness among medical special needs populations
}

\author{
Leslie Meyer, Kristina Vatcheva, Stephanie Castellanos and Belinda Reininger* \\ University of Texas Health Science Center at Houston - School of Public Health, Brownsville Regional Campus, Brownsville, \\ TX, USA
}

A medical special needs (MSN) assessment was conducted among 3088 respondents in a hurricane prone area. The sample was female (51.7\%), Hispanic (92.9\%), aged $>45$ years $(51 \%)$, not insured for health (59.2\%), and with an MSN (33.2\%). Barriers to preparedness were characterized for all households, including those with inhabitants reporting MSN ranging from level 0 (mild) to level 4 (most severe). Multivariable logistic

OPEN ACCESS

Edited by:

Scott C. Carvajal,

University of Arizona, USA

Reviewed by:

Christina Beach Thielst,

TOWER Patient Experience

Consulting Group, USA

Daniel Martinez Garcia,

Médecins Sans Frontières, Spain

*Correspondence:

Belinda Reininger,

University of Texas Health Science

Center at Houston - School of Public

Health, Brownsville Regional Campus,

One West University BIvd.,

Brownsville, TX 78520, USA

belinda.m.reininger@uth.tmc.edu

Specialty section:

This article was submitted to Public Health Education and Promotion,

a section of the journal

Frontiers in Public Health

Received: 19 March 2015

Accepted: 11 August 2015 Published: 02 September 2015

Citation:

Meyer L, Vatcheva K, Castellanos S and Reininger $B$ (2015) Barriers to disaster preparedness among medical special needs populations.

Front. Public Health 3:205.

doi: 10.3389/fpubh.2015.00205 regression tested associations between hurricane preparedness and barriers to evacuation by level of MSN. A significant interaction effect between number of evacuation barriers and MSN was found. Among households that reported individuals with level $0 \mathrm{MSN}$, the odds of being unprepared increased $18 \%$ for each additional evacuation barrier $[\mathrm{OR}=1.18,95 \% \mathrm{Cl}(1.08,1.30)]$. Among households that reported individuals with level $1 \mathrm{MSN}$, the odds of being unprepared increased $29 \%$ for each additional evacuation barrier $[\mathrm{OR}=1.29,95 \% \mathrm{Cl}(1.11,1.51)]$. Among households that reported individuals with level $3 \mathrm{MSN}$, the odds of being unprepared increased $68 \%$ for each additional evacuation barrier [OR $=1.68,95 \% \mathrm{Cl}(1.21,1.32)]$. MSN alone did not explain the probability of unpreparedness, but rather MSN in the presence of barriers helped explain unpreparedness.

Keywords: Hispanics, disaster preparedness, evacuation barriers, medical special needs, hurricane

\section{Introduction}

Lack of preparedness for natural disasters stresses an already overwhelmed public health and medical system when disaster strikes $(1,2)$. For individuals, disaster preparedness involves the steps taken beforehand to identify and assemble adequate supplies for household members, including food, water, and medical needs, as well as establishing an emergency plan that should include possible evacuation shelters (3). However, lack of disaster preparedness is common and can increase potential damage, injury to self, and mortality (4). At the system level, there is a need for greater understanding of how organizations charged with managing disasters interact with the public before and during an emergency situation, and how these entities respond (1). For professionals responsible for directing public health disaster responses, preparedness includes identifying which populations may be most affected by the disaster and who will need priority responses to avert danger (5). Factors to consider include limited access and exposure to natural, technical, and social resources (5) and disproportionate access to medical care during extreme weather events (6).

The National Center for Emergency Medical (2) emphasizes that an effective and efficient evacuation requires the rapid assessment of individuals in need of assistance, the subsequent evacuation of those individuals, and their proper care (7). For example, individuals with limited 
financial resources may find it difficult to purchase extra food, water, or medications in preparation for a disaster and in the event of an evacuation. Others in need may include those with poor health, lack of social support networks, without knowledge of evacuation centers, without access to reliable transportation, or without knowledge of what to do in the event of an evacuation (8).

Almost 50\% of adults in the US do not have emergency supplies in case of a disaster (9). This is particularly true among Hispanics who have been found to be the least prepared compared to other racial and ethnic groups (10-13). Previous studies have shown that Hispanics are less likely compared to Whites and Blacks to have a 3-day food supply, 3-day supply of medication, a working battery-operated radio, or a flashlight (11). Primarily Spanishspeaking Hispanics, compared to primarily English-speaking Hispanics also report lower levels of preparation in these four categories, but are more likely to have an emergency evacuation plan and 3-day supply of water (11). Differences in disaster preparedness have been documented (11-15), but few studies have examined if the presence of medical special needs (MSN) influences disaster preparedness.

The Special Needs Assessment for Katrina Evacuees (SNAKE) project, conducted by the National Organization on Disability, shed light on numerous barriers and policies associated with negative experiences shared by individuals with disabilities who evacuated to shelters when Hurricane Katrina struck the Gulf Coast in 2005 (16). Barriers included access to reliable and accessible shelters with protocols in place to provide services for individuals with disabilities and MSN (16). Individuals with MSN have decreased access to appropriate transportation for evacuation (17), may require additional equipment that would need transportation (18), and have limited access to an appropriate host shelter due to the level of care required (17).

Research on vulnerable populations and disaster preparedness geographically is limited $(10,19,20)$. Previous studies have surveyed the general Texas population for evacuation intentions and experiences $(21,22)$. An assessment of disaster preparedness determined that slightly more than half (59\%) of residents in this three county area known as the Texas Rio Grande Valley stated that they were prepared for a hurricane (13). Previous research has not reported differences between disaster preparedness and MSN levels of vulnerability among a population in a disaster prone region.

This study aims to characterize disaster preparedness and its barriers among vulnerable populations living in a hurricane prone area. Specifically, we will compare disaster preparedness and barriers to evacuation across households reporting MSN and households without MSN. We hypothesize that households with higher levels of MSN will experience more barriers to evacuation and less preparedness for disasters.

\section{Materials and Methods}

\section{Sample}

The study sample included household respondents surveyed as part of the Medical Special Needs Assessment of the Lower Rio Grande Valley (23). The survey was administered to 3088 individuals in 172 census tracts and was weighted to represent the 696,349 individuals across Cameron, Hidalgo, and Willacy
Counties, Texas. These are counties located on or near the Texas Coastline, an area prone to hurricanes. The methods for data collection have previously been reported $(12,23)$.

The assessment was conducted by trained community health workers who interviewed, with signed informed consent, one adult per household. Thirty surveys were completed from each of 100 census tracts and were administered in English or Spanish, depending upon the respondent's preferred language.

\section{Measurement of Medical Special Needs}

Previously defined levels of MSN, customary in the state of Texas in 2007 (23), are described in Table 1 and were measured in the current study. MSN level 5 includes individuals in institutional settings, such as hospitals, long-term care facilities, assisted living facilities, or state schools, and is not assessed in the present study because data collection was conducted solely in homes.

\section{Measurement of Disaster Preparedness}

To assess disaster preparedness, respondents were asked "How prepared are you if a major hurricane were to strike your community during the next hurricane season?" Responses of "very" and "somewhat" were identified as "prepared" for a hurricane. Responses of "not too" and "not at all" were identified as "not prepared" for a hurricane.

\section{Measurement of Barriers}

A total of 15 barriers to evacuation for a hurricane were assessed based on a previous instrument (24). A scale score was calculated by summing the number of affirmative responses to each barrier. This scale score was used in multivariable analysis models.

\section{Sociodemographic Variables}

Sociodemographic variables used to characterize the population included gender, age, educational attainment (elementary/middle school, high school, or college/technical), marital status (married or not married), ethnicity, acculturation (high adherence with Spanish, biculturalism, or high adherence with English), health status (poor, fair, good, very good, or excellent), health insurance, homeowner/renter's insurance, household size, household income, adults in household ages 65 years and older, children in household under the age of 10 , cash savings, and distance to shore.

\section{TABLE 1 | Level of medical special needs (MSN)}

No special needs: no medical needs and no required assistance

Level 0: no medical needs, but require transportation assistance for evacuation

Level 1: dependent on others for routine care (eating, walking, toileting, etc.) and children under 18 without adult supervision

Level 2: physical or developmental disabilities, such as blindness, significant hearing impairment, amputation, deafness, and mental retardation

Level 3: require assistance with medical care administration, monitoring by nurse, dependent on equipment, assistance with medications, and mental health disorders

Level 4: persons outside an institutional facility care setting, who require extensive medical oversight (i.e., IV, chemotherapy, life support equipment, morbidly obese)

Levels defined as by the State of Texas Hurricane Evacuation and Mass Care Plan, 2007. 


\section{Statistical Analysis}

Population estimates for the parameters and their SEs were generated by taking into account the study design features and incorporating the sampling weights. For descriptive purposes, categorical variables were summarized in unweighted frequencies and weighted percentages. Continuous variables were summarized using weighted means and their SEs. In univariable weighted logistic regression analysis, we determined association between variables and the dichotomized variable for self-reported preparedness. Results are presented with weighted odds ratios and their $95 \%$ confidence intervals. In addition, an ordinal variable with the six levels of MSN was created. Since the assumptions for ordinal logistic regression did not hold, weighted multinomial logit models were fitted to obtain the odds of higher levels of MSN versus no MSN. We built a weighted multivariable logistic regression model for self-reported preparedness (no/yes), including variables with Rao-Scott design-adjusted chi-square test statistics $p$-value $<0.10$ from the univariable analysis. Harmful multicollinearity between the independent variables considered in the model was not found (VIF $<1.5$ ). The linearity assumption in the logit for continuous variables was checked. The contribution of interactions to the fit of the model was tested using designadjusted Wald test significance level $p<0.05$ and the statistically non-significant interactions were removed from the model. The preliminary final model was tested for goodness-of-fit applying Archer and Lemeshow's F-adjusted mean residual goodness-of-fit test using (25). All other weighted analyses were conducted using (26). All statistical testing was two-sided and was performed using a significance (alpha) level of 0.05 .

\section{Results}

The final sample for this study consisted of a total of 2981 respondents (Table 2). Slightly more than half of respondents were female $(51.7 \%)$, aged 45 years or older $(51 \%)$, with a mean age of 46.9 (SE 0.79 ). Only $18.3 \%$ of respondents had a college or technical education and $73.5 \%$ were married. The sample was predominantly Hispanic (92.9\%) with high acculturation levels of adherence to the Spanish language (58.4\%). A low percentage (5.1\%) of respondents was in excellent health, $59.2 \%$ were without any form of health insurance, and $61.4 \%$ were homeowner uninsured. The majority household size was between 3 and 5 people (58.7\%) with a household income below \$35,000 (87.6\%). Among households, $12.9 \%$ had at least one adult aged 65 or older; $40.8 \%$ had at least one child under the age of $10 ; 40.8 \%$ had at least $\$ 300$ in cash savings; the mean distance from the shore was 41.6 miles (SE 1.03); and 66.8\% had no MSN household members.

On average respondents with $<8$ years of education had significantly higher numbers of evacuation barriers (mean 6.2, SE $0.16, p=0.0406$ ) in comparison to those with a college or technical education (mean 5.4, SE 0.35) (Table 2). In addition, respondents at any level of self-reported health conditions (poor: $p=0.0002$, fair: $p<0.0001$, good: $p<0.0001$, very good: $p=0.0071)$ reported significantly higher average number of evacuation barriers compared to those with excellent self-reported health. Smaller households of size $1-2$ people $(p<0.0001)$ or $3-5$ people $(p=0.0021)$ reported significantly lower average number
TABLE 2 | Demographics characteristics of respondents and households and reported barriers to evacuation $(n=2981)$

\begin{tabular}{|c|c|c|c|}
\hline & $n$ (weighted \%) & $\begin{array}{c}\text { Total } \\
\text { number of } \\
\text { evacuation } \\
\text { barriers } \\
\text { Mean (SE) }\end{array}$ & $\begin{array}{l}\text { Difference } \\
\text { in mean }\end{array}$ \\
\hline \multicolumn{4}{|c|}{ RESPONDENT LEVEL } \\
\hline \multicolumn{4}{|c|}{ Gender } \\
\hline Male & 760 (48.3) & $5.8(0.23)$ & 0.6728 \\
\hline Female $^{a}$ & $2221(51.7)$ & $5.9(0.12)$ & \\
\hline \multicolumn{4}{|l|}{ Age } \\
\hline $18-44$ years $^{a}$ & $1460(49.0)$ & $5.8(0.23)$ & 0.7899 \\
\hline$\geq 45$ years & $1520(51.0)$ & $5.9(0.12)$ & \\
\hline \multicolumn{4}{|l|}{ Education } \\
\hline$\leq 8$ years & $1123(38.5)$ & $6.2(0.16)$ & 0.0406 \\
\hline High school & $1235(43.2)$ & $5.7(0.22)$ & 0.5145 \\
\hline College/technical ${ }^{a}$ & $529(18.3)$ & $5.4(0.35)$ & \\
\hline \multicolumn{4}{|l|}{ Marital status } \\
\hline Not married & $901(26.5)$ & $5.5(0.21)$ & 0.003 \\
\hline Married $^{\mathrm{a}}$ & $2080(73.5)$ & $6.0(0.16)$ & \\
\hline \multicolumn{4}{|l|}{ Ethnicity } \\
\hline Hispanic & 2738 (92.9) & $5.9(0.17)$ & 0.1317 \\
\hline Non-Hispanic ${ }^{a}$ & $243(7.1)$ & $5.1(0.52)$ & \\
\hline \multicolumn{4}{|l|}{ Acculturation } \\
\hline Spanish & $1780(58.4)$ & $6.0(0.14)$ & 0.315 \\
\hline Bicultural & 903 (32.1) & $5.8(0.26)$ & 0.5429 \\
\hline English $^{a}$ & $267(9.5)$ & $5.4(0.50)$ & \\
\hline \multicolumn{4}{|l|}{ Health condition } \\
\hline Poor & 65 (1.9) & $6.4(0.33)$ & 0.0002 \\
\hline Fair & $537(15.4)$ & $6.2(0.26)$ & $<0.0001$ \\
\hline Good & $1677(57.4)$ & $6.0(0.13)$ & $<0.0001$ \\
\hline Very good & $518(20.1)$ & $5.6(0.38)$ & 0.0071 \\
\hline Excellent $^{a}$ & $163(5.1)$ & $4.4(0.39)$ & \\
\hline \multicolumn{4}{|l|}{ Health insurance } \\
\hline Insured & $1213(40.8)$ & $5.7(0.21)$ & 0.3388 \\
\hline Not insured ${ }^{a}$ & $1758(59.2)$ & $5.9(0.18)$ & \\
\hline \multicolumn{4}{|c|}{ Homeowner's insurance } \\
\hline Insured & $1140(38.6)$ & $5.6(0.23)$ & 0.1927 \\
\hline Uninsured $^{\mathrm{a}}$ & $1620(61.4)$ & $6.0(0.21)$ & \\
\hline \multicolumn{4}{|c|}{ HOUSEHOLD LEVEL } \\
\hline \multicolumn{4}{|c|}{ Household size } \\
\hline 1-2 people & $710(24.0)$ & $5.3(0.21)$ & $<0.0001$ \\
\hline 3-5 people & $1737(58.7)$ & $5.9(0.20)$ & 0.0021 \\
\hline$>5$ people ${ }^{a}$ & $527(17.4)$ & $6.5(0.17)$ & \\
\hline \multicolumn{4}{|l|}{ Income } \\
\hline$<10,000$ & 902 (32.8) & $6.2(0.18)$ & 0.1262 \\
\hline 10,000 to $<15,000$ & $676(27.9)$ & $6.1(0.30)$ & 0.1944 \\
\hline 15,000 to $<25,000$ & $394(17.5)$ & $5.7(0.22)$ & 0.421 \\
\hline 25,000 to $<35,000$ & $217(9.7)$ & $5.7(0.32)$ & 0.4481 \\
\hline$\geq 35,000^{\mathrm{a}}$ & $278(12.4)$ & $5.3(0.53)$ & \\
\hline \multicolumn{4}{|l|}{ Adults $>65$ years } \\
\hline$\geq 1$ person & $430(12.9)$ & $6.0(0.19)$ & 0.3029 \\
\hline \multicolumn{4}{|l|}{ Children $<10$ years } \\
\hline$\geq 1$ person & $1270(41.6)$ & $5.9(0.18)$ & 0.2976 \\
\hline \multicolumn{4}{|l|}{ Cash savings } \\
\hline$\geq \$ 300$ & $1164(40.8)$ & $5.6(0.21)$ & 0.0527 \\
\hline \multicolumn{4}{|c|}{ Level of medical needs } \\
\hline No medical needs & $1976(66.8)$ & $5.5(0.19)$ & 0.1023 \\
\hline Level 0 & $500(16.1)$ & $6.4(0.23)$ & 0.9401 \\
\hline Level 1 & $251(9.2)$ & $6.0(0.34)$ & 0.4623 \\
\hline Level 2 & $66(2.0)$ & $5.9(0.38)$ & 0.4195 \\
\hline Level 3 & $83(3.3)$ & $8.4(0.46)$ & 0.0008 \\
\hline Level $4^{\mathrm{a}}$ & $78(2.6)$ & $6.4(0.53)$ & \\
\hline
\end{tabular}

${ }^{a}$ Reference group. 
TABLE 3 | Individual level characteristics by hurricane preparedness.

\begin{tabular}{|c|c|c|c|c|}
\hline & $n$ (weighted \%) & Not prepared (weighted \%) & Prepared (weighted \%) & OR (95\% Cl) \\
\hline \multicolumn{5}{|l|}{ Gender } \\
\hline Male & $747(40.5)$ & $268(59.5)$ & $479(50.2)$ & $0.85(0.70,1.03)$ \\
\hline Female $^{a}$ & $2176(51.5)$ & $907(45.58)$ & $1269(55.5)$ & \\
\hline \multicolumn{5}{|l|}{ Age } \\
\hline $18-44$ & $1442(49.3)$ & $652(48.6)$ & $790(51.4)$ & $1.63(1.30,2.05)$ \\
\hline $45-75+^{a}$ & $1480(50.7)$ & $522(36.7)$ & 958 (63.3) & \\
\hline Mean (SE) & $46.9(0.8)$ & $44.0(1.0)$ & $49.0(0.8)$ & $0.98(0.975,0.989)$ \\
\hline \multicolumn{5}{|l|}{ Education } \\
\hline$\leq 8$ years & 1097 (38.5) & $459(44.2)$ & $638(55.8)$ & $1.45(1.01,2.09)$ \\
\hline HS diploma & $1213(43.2)$ & $508(44.6)$ & $705(55.4)$ & $1.48(1.04,2.10)$ \\
\hline College/technical $^{a}$ & $521(18.3)$ & $173(35.3)$ & $348(64.7)$ & \\
\hline \multicolumn{5}{|l|}{ Marital status } \\
\hline Not married & 877 (26.3) & $353(40.7)$ & 524 (59.3) & $0.90(0.72,1.12)$ \\
\hline Married $^{\mathrm{a}}$ & $2046(73.7)$ & $882(43.3)$ & $1224(56.7)$ & \\
\hline \multicolumn{5}{|l|}{ Ethnicity } \\
\hline Hispanic & $2681(92.8)$ & $1101(43.5)$ & $1580(56.5)$ & $1.68(0.99,2.86)$ \\
\hline White $^{a}$ & $242(7.2)$ & 74 (31.3) & $168(68.7)$ & \\
\hline \multicolumn{5}{|l|}{ Acculturation } \\
\hline Spanish & $1748(58.6)$ & $750(45.6)$ & $998(54.4)$ & $1.32(0.81,2.14)$ \\
\hline Bicultural & 880 (31.8) & $332(38.1)$ & $548(61.9)$ & $0.97(0.59,1.58)$ \\
\hline English $^{a}$ & $266(9.6)$ & $82(38.9)$ & $184(61.1)$ & \\
\hline \multicolumn{5}{|l|}{ Health condition } \\
\hline Poor & $58(1.8)$ & $31(50.0)$ & 27 (50.0) & $1.90(0.84,4.30)$ \\
\hline Fair & $526(15.3)$ & $233(47.7)$ & $293(52.3)$ & $1.73(0.98,3.06)$ \\
\hline Good & $1641(57.3)$ & $668(43.6)$ & $973(56.4)$ & $1.47(0.86,2.51)$ \\
\hline Very good & $515(20.4)$ & $185(36.8)$ & $330(63.2)$ & $1.11(0.65,1.89)$ \\
\hline Excellent $^{\mathrm{a}}$ & $162(5.2)$ & $48(34.5)$ & $114(65.5)$ & \\
\hline \multicolumn{5}{|l|}{ Health insurance } \\
\hline Insured & $1184(40.6)$ & $411(36.9)$ & $773(63.1)$ & $0.67(0.51,0.88)$ \\
\hline Uninsured $^{\mathrm{a}}$ & $1729(59.4)$ & $762(46.6)$ & $967(53.4)$ & \\
\hline \multicolumn{5}{|c|}{ Homeowner's insurance } \\
\hline Insured & $1114(38.4)$ & 357 (34.6) & $757(65.4)$ & $0.60(0.45,0.80)$ \\
\hline Uninsured $^{\mathrm{a}}$ & $1597(61.6)$ & $717(47.0)$ & $880(53.0)$ & \\
\hline
\end{tabular}

Bold font indicates statistical significance.

SE, standard error; HS, high school; HA, high adherence.

${ }^{a}$ Reference group.

The percentages, odds ratios, and 95\% confidence intervals are weighted.

of evacuation barriers compared to households with more than 5 people. Households reporting an individual requiring assistance with medical care administration (MSN Level 4) reported significantly higher average number of evacuation barriers (mean 8.4, SE 0.46) compared to households reporting an individual requiring extensive medical oversight (MSN Level 5) (mean 6.4, SE 0.53; $p=0.0008)$.

Using univariable logistic regression analyses, the odds of being unprepared for a hurricane (Table 3) were 1.63 times higher for respondents aged between 18 and 44 years [95\% CI $(1.30,2.05)$ ] than the odds for respondents aged 45 years or older. Similarly, the odds of being unprepared were higher for those with 8 years of education or less $[\mathrm{OR}=1.45,95 \% \mathrm{CI}(1.01,2.10)]$ or a high school diploma $[\mathrm{OR}=1.48,95 \% \mathrm{CI}(1.04,2.10)]$ compared to those with a college or technical education. In addition, respondents who reported having health insurance were $33 \%[\mathrm{OR}=0.67,95 \% \mathrm{CI}$ $(0.51,0.88)]$ more prepared compared to those without health insurance, and respondents with homeowner's insurance were $40 \%[\mathrm{OR}=0.60,95 \% \mathrm{CI}(0.45,0.80)]$ more prepared compared to those without homeowner's insurance.

Household size also had a significant effect on preparedness (Table 4). Respondents of smaller households, 1-2 people, or
3-5 people were $40 \%$ [95\% CI $(0.28,0.56)]$ and 58\% [95\% CI $(0.46,0.73)]$, respectively, less likely to be unprepared compared to larger households of more than 5 people. Households with lower annual income were more likely to be unprepared compared to households with an income $>\$ 35,000$. Respondents reporting higher numbers of evacuation barriers were significantly more likely to be unprepared for a hurricane. With a 1 count increase in number of evacuation barriers, the expected increase in the odds of being unprepared was $3 \%$. The evacuation barriers of "the entire family cannot leave," "think the roads would be too crowded to leave," "worry possessions would be stolen or damaged," "cannot afford to leave (travel expenses)," "think evacuating will be dangerous," "will be safe at home," and "unable to work will mean being replaced" were significantly associated with evacuation unpreparedness, where very high odds of being unprepared were observed in respondents where "the entire family cannot leave" $[\mathrm{OR}=2.62,95 \% \mathrm{CI}$ $(2.00,3.40)]$, in respondents who "think the roads would be too crowded to leave" $[\mathrm{OR}=2.37,95 \%$ CI $(1.76,3.19)]$, and in respondents who reported that being "unable to work will mean being replaced" $[\mathrm{OR}=2.25,95 \% \mathrm{CI}(1.55,3.27)]$. Additionally, respondents reporting a higher level of MSN were more 


\begin{tabular}{|c|c|c|c|c|}
\hline & $n$ (weighted \%) & Not prepared (weighted \%) & Prepared (weighted \%) & OR (5\% Cl) \\
\hline \multicolumn{5}{|l|}{ Household size } \\
\hline 1-2 people & $688(23.6)$ & $233(33.4)$ & 455 (66.6) & $0.40(0.28,0.56)$ \\
\hline 3-5 people & $1710(59.0)$ & $680(42.3)$ & $1030(57.7)$ & $0.58(0.46,0.73)$ \\
\hline$>5$ people $^{a}$ & $519(17.4)$ & $260(56.0)$ & $259(44.0)$ & \\
\hline \multicolumn{5}{|l|}{ Income } \\
\hline$<\$ 10,000$ & $878(32.3)$ & $378(45.4)$ & $500(54.6)$ & $2.13(1.32,3.42)$ \\
\hline$\$ 10,000-\$ 14,999$ & $661(27.9)$ & $301(48.5)$ & $360(51.5)$ & $2.41(1.50,3.89)$ \\
\hline$\$ 15,000-\$ 24,999$ & $394(17.8)$ & $145(40.6)$ & $249(59.4)$ & $1.75(1.11,2.76)$ \\
\hline$\$ 25,000-\$ 34,999$ & $216(9.7)$ & $83(45.0)$ & $133(55.0)$ & $2.09(1.22,3.57)$ \\
\hline$\geq \$ 35,000^{a}$ & $274(12.4)$ & $77(28.1)$ & $197(71.9)$ & \\
\hline \multicolumn{5}{|l|}{ Adults $>65$ years } \\
\hline$\geq 1$ person & $414(12.8)$ & $127(32.0)$ & $287(68.0)$ & $0.59(0.44,0.80)$ \\
\hline \multicolumn{5}{|l|}{$\bar{C}$ hildren $<10$ years } \\
\hline$\geq 1$ person & $1256(41.9)$ & $564(48.0)$ & $692(52.0)$ & $1.46(1.15,1.85)$ \\
\hline \multicolumn{5}{|l|}{ Cash savings } \\
\hline$\geq \$ 300$ & $1145(41.0)$ & $325(32.7)$ & $820(67.3)$ & $0.50(0.39,0.63)$ \\
\hline \multicolumn{5}{|l|}{ Distance from shore (miles) } \\
\hline Mean (SE) & $41.6(1.02)$ & $46.6(1.1)$ & $38.4(1.1)$ & $1.03(1.03,1.04)$ \\
\hline \multicolumn{5}{|l|}{ Evacuation barriers } \\
\hline 1. The entire family cannot leave & $2016(72.6)$ & $943(48.6)$ & $1073(51.4)$ & $2.62(2.00,3.40)$ \\
\hline 2. Think road would be too crowded to leave & $1991(71.1)$ & $909(48.4)$ & $1082(51.6)$ & $2.37(1.76,3.19)$ \\
\hline 3. Worry possessions stolen/damaged & $1971(69.5)$ & $836(44.5)$ & $1135(55.5)$ & $1.31(1.04,1.65)$ \\
\hline 4. Cannot afford to leave (travel expenses) & $1620(56.9)$ & $710(45.4)$ & $910(54.6)$ & $1.30(1.01,1.68)$ \\
\hline 5. Do not know where to go & $1564(55.5)$ & $662(45.0)$ & $902(55.0)$ & $1.25(0.96,1.62)$ \\
\hline 6. Do not have transportation & $1287(46.7)$ & $542(43.8)$ & $745(56.2)$ & $1.10(0.83,1.45)$ \\
\hline 7. Think shelters might be unsafe or unsanitary & $1227(40.5)$ & $492(42.1)$ & $735(57.9)$ & $0.97(0.77,1.21)$ \\
\hline 8. Have medical/physical problems & 432 (12.8) & $177(46.0)$ & $255(54.0)$ & $1.18(0.88,1.56)$ \\
\hline 9. Think evacuating will be dangerous & $1146(41.8)$ & $530(50.2)$ & $616(49.8)$ & $1.71(1.30,2.25)$ \\
\hline 10. Work during hurricane & $391(12.7)$ & $135(36.3)$ & $256(63.7)$ & $0.74(0.51,1.07)$ \\
\hline 11. Do not want to leave pet & $893(31.0)$ & $367(45.0)$ & $526(55.0)$ & $1.15(0.83,1.62)$ \\
\hline 12. Will be safe at home & $1269(45.5)$ & $584(49.1)$ & $685(50.9)$ & $1.63(1.21,2.21)$ \\
\hline 13. Unable to work will mean being replaced & $453(16.4)$ & $231(59.3)$ & $222(40.7)$ & $2.25(1.55,3.27)$ \\
\hline 14. No proper documents to leave area & $1213(45.8)$ & $500(42.5)$ & $713(57.5)$ & $1.00(0.76,1.31)$ \\
\hline 15. Care for someone who cannot leave & $320(9.5)$ & $118(42.0)$ & $202(58.0)$ & $0.98(0.69,1.38)$ \\
\hline \multicolumn{5}{|l|}{ No. evacuation barriers } \\
\hline Mean (SE) & $5.8(0.2)$ & $6.4(0.2)$ & $5.4(0.2)$ & $1.13(1.07,1.19)$ \\
\hline \multicolumn{5}{|l|}{ Level of medical needs } \\
\hline No medical needs ${ }^{a}$ & 1932 (66.7) & $681(36.6)$ & $1251(63.4)$ & $1.88(1.37,2.58)$ \\
\hline Level 0 & 498 (16.3) & $241(52.0)$ & $257(48.0)$ & $2.46(1.64,3.70)$ \\
\hline Level 1 & $245(9.1)$ & $137(58.7)$ & $108(41.3)$ & $1.52(0.78,2.96)$ \\
\hline Level 2 & $65(2.0)$ & $25(46.7)$ & $40(53.3)$ & $3.82(2.08,7.02)$ \\
\hline Level 3 & $82(3.3)$ & $50(68.8)$ & $32(31.2)$ & $1.19(0.65,2.19)$ \\
\hline Level 4 & $75(2.6)$ & $28(40.8)$ & $47(59.2)$ & \\
\hline
\end{tabular}

Bold font indicates statistical significance.

SE, standard error.

${ }^{a}$ Reference group.

The percentages, odds ratios, and 96\% confidence intervals are weighted.

likely to be unprepared compared to those reporting no MSN. Specifically, the odds of respondents reporting an individual requiring assistance with medical care administration (MSN Level 4) were 3.82 times higher [ $95 \%$ CI $(2.08,7.02)]$ to be unprepared for an evacuation compared to those reporting no MSN. Likewise, respondents reporting an individual who depends on others for routine care (MSN Level 1) were 2.46 times more likely to be unprepared [95\% CI $(1.64,3.70)]$ compared to those with no MSN. Respondents reporting an individual requiring transportation assistance (MSN Level 0) were 1.88 times more likely to be unprepared $[95 \%$ CI $(1.37,2.58)]$ compared to those with no MSN.

Univariable multinomial logistic regression analyses tested the individual, household, and evacuation barriers by MSN (data not shown). The odds of level 0 MSN versus no MSN was 26\% lower for males compared to females $[\mathrm{OR}=0.74,95 \% \mathrm{CI}(0.55,1)]$. We also found the odds of level 0 MSN versus no MSN toss be $71 \%$ lower in respondents aged greater than 45 years in comparison to those aged 44 years or younger [OR $=0.29,95 \%$ CI $(0.21$, $0.41)$. The odds of level 0 MSN versus no MSN was 35\% lower for unmarried respondents compared to married respondents $[\mathrm{OR}=0.65,95 \%$ CI $(0.48,0.9)]$. Respondents reporting higher numbers of evacuation barriers were significantly more likely to be level 0 MSN. With a 1 number increase in evacuation barriers, an expected increase in the odds of reporting level 0 MSN was $13 \%[\mathrm{OR}=1.13,95 \% \mathrm{CI}(1.05,1.21)]$. Higher odds of reporting level $0 \mathrm{MSN}$ were observed when respondents also reported "the entire family cannot leave" $[\mathrm{OR}=6.58,95 \% \mathrm{CI}(3.73,11.58)]$, or 
that "the roads would be too crowded to leave" [OR $=2.63,95 \%$ CI $(1.75,3.96)]$, or "unable to work will mean being replaced" $[\mathrm{OR}=3.03,95 \% \mathrm{CI}(2.00,4.59)]$.

The multivariable logistic regression model for the probability of being unprepared for a hurricane (Table 5) shows that after adjusting for ethnicity, adults in household 65 years or older, cash savings of at least $\$ 300$, income, age of respondent by household size, distance from shore and level of MSN and number of evacuation barriers, the odds of Hispanics to be unprepared for a hurricane were $49 \%$ lower in comparison to non-Hispanics $[\mathrm{OR}=0.51,95 \% \mathrm{CI}(0.27,0.95)]$. In addition households with incomes between $\$ 25,000$ and $\$ 35,000$ had 1.96 [95\% CI (1.13, 3.39)] times higher odds of being unprepared compared to those with income greater than $\$ 35,000$. The odds of households with at least one adult aged 65 years or older to be unprepared is $32 \%$ $[\mathrm{OR}=0.68,95 \% \mathrm{CI}(0.47,0.98)]$ lower compared to households with no adults aged 65 years or older. Additionally, there was a significant statistical interaction between age and household size, where the effect of age on unpreparedness was significant only in household sizes with $1-2$ people $[\mathrm{OR}=0.98,95 \%$ CI $(0.97$, $0.99)]$. This result indicates that for every year increase in age of respondents among households with 1-2 people, there were slightly decreased odds of being unprepared. For every one mile increase in distance from the shore, the odds of being unprepared increased by $3 \%$ [OR $=1.03,95 \%$ CI $(1.02,1.04)]$.

A significant interaction between the number of evacuation barriers and the levels of MSN resulted in varying effects of being unprepared across the MSN levels. Among households with individuals requiring transportation assistance (MSN Level 0), for every one additional increase in the number of evacuation barriers the odds of being unprepared increased by $18 \%$ [OR $=1.18,95 \%$ CI $(1.08,1.30)]$. Among households that reported individuals who depend on others for routine care (MSN Level 1), for every one additional increase in the number of evacuation barriers the odds of being unprepared increased by $29 \%$ [OR $=1.29,95 \%$ CI $(1.11$, 1.51)]. Also, among households that reported individuals who require assistance with medical care administration (MSN Level 3 ), for every one additional increase in the number of evacuation barriers the odds of being unprepared increased $68 \%[\mathrm{OR}=1.68$, 95\% CI $(1.21,1.32)]$.

\section{Discussion}

This study examined preparedness for a hurricane and barriers to evacuation among households reporting MSN and households without MSN along the South Texas Gulf Coast. We hypothesized that households with higher levels of MSN would experience more barriers to evacuation and less preparedness for disasters. Our hypothesis was not proven because the effect of MSN on preparedness is more complex than our proposed simplistic linear hypothesis.

Medical special needs alone did not explain the probability of unpreparedness, but rather MSN in the presence of barriers played a role in explaining unpreparedness. As the number of barriers increased, households reporting the presence of individuals with MSN of levels 0,1 , and 3 were significantly more likely to be unprepared, but this interaction effect was not significant in households reporting the presence of individuals with levels 2 and
TABLE 5 | Multivariable logistic regression model for probability of being unprepared for effects

\begin{tabular}{|c|c|}
\hline & $\begin{array}{l}\text { Unprepared for hurricane } \\
\text { OR }(95 \% \mathrm{Cl})\end{array}$ \\
\hline \multicolumn{2}{|l|}{ RESPONDENT LEVEL } \\
\hline \multicolumn{2}{|l|}{ Ethnicity } \\
\hline Hispanics & $0.51(0.27,0.95)$ \\
\hline \multicolumn{2}{|l|}{ Non-Hispanics ${ }^{a}$} \\
\hline \multicolumn{2}{|l|}{ Adults $>65$ years } \\
\hline$\geq 1$ person & $0.68(0.47,0.98)$ \\
\hline \multicolumn{2}{|l|}{$\overline{\text { No adults }}>65^{\mathrm{a}}$} \\
\hline \multicolumn{2}{|l|}{ Cash savings } \\
\hline$\geq \$ 300$ & $0.60(0.48,0.74)$ \\
\hline \multicolumn{2}{|l|}{$<\$ 300^{\mathrm{a}}$} \\
\hline \multicolumn{2}{|l|}{ Income } \\
\hline$<\$ 10,000$ & $1.52(0.97,2.37)$ \\
\hline$\$ 10,000-\$ 14,999$ & $1.39(0.87,2.22)$ \\
\hline$\$ 15,000-\$ 24,999$ & $1.16(0.74,1.83)$ \\
\hline$\$ 25,000-\$ 34,999$ & $1.96(1.13,3.39)$ \\
\hline \multicolumn{2}{|l|}{$\geq \$ 35,000^{\mathrm{a}}$} \\
\hline \multicolumn{2}{|l|}{ HOUSEHOLD LEVEL } \\
\hline \multicolumn{2}{|l|}{ Age of respondent by household size } \\
\hline Age of respondent in household of 1-2 people & $0.98(0.97,0.99)$ \\
\hline Age of respondent in household of 3-5 people & $1.01(0.99,1.03)$ \\
\hline Age of respondent in household of $>5$ people & $1(0.99,1.01)$ \\
\hline Distance from shore (miles) & $1.03(1.02,1.04)$ \\
\hline \multicolumn{2}{|l|}{ Level of medical special needs } \\
\hline $\begin{array}{l}\text { Number of evacuation barriers in individuals } \\
\text { with No MSN }\end{array}$ & $0.98(0.93,1.03)$ \\
\hline $\begin{array}{l}\text { Number of evacuation barriers in individuals } \\
\text { with Level O MSN }\end{array}$ & $1.18(1.08,1.30)$ \\
\hline $\begin{array}{l}\text { Number of evacuation barriers in individuals } \\
\text { with Level } 1 \mathrm{MSN}\end{array}$ & $1.29(1.11,1.51)$ \\
\hline $\begin{array}{l}\text { Number of evacuation barriers in individuals } \\
\text { with Level } 2 \mathrm{MSN}\end{array}$ & $1.14(0.86,1.52)$ \\
\hline $\begin{array}{l}\text { Number of evacuation barriers in individuals } \\
\text { with Level } 3 \mathrm{MSN}\end{array}$ & $1.68(1.21,2.32)$ \\
\hline $\begin{array}{l}\text { Number of evacuation barriers in individuals } \\
\text { with Level } 4 \mathrm{MSN}\end{array}$ & $0.96(0.79,1.16)$ \\
\hline
\end{tabular}

Bold font indicates statistical significance.

MSN, medical special needs.

${ }^{a}$ Reference group.

$4 \mathrm{MSN}$ and among households with no MSN members. Therefore, it was not as simple as the higher the level of MSN the greater the unpreparedness. Likewise, there is no simple explanation for these findings, but rather we propose potential scenarios to shed light on the complexities. For households (MSN Level 0) that need transportation assistance during an evacuation, the barriers of feeling the family will be safe at home and not having travel expenses among other barriers may have led respondents to report being unprepared for a hurricane. For households (MSN Level 1) with either small children or adults who need help with routine care, the barrier of the roads will be too crowded to leave may be tied to respondents reporting being unprepared for a hurricane. Finally, for households (MSN Level 3) that have individuals who are monitored by a nurse, receive medication assistance, are dependent on equipment, or have a mental health disorder, the barrier of the entire family not being able to leave, in addition to other barriers, may have influenced respondents reporting being unprepared for a hurricane. In essence, it appears that once a household reports MSN where individuals are primarily dependent on others in the household for care or have medication or 
equipment needs and the barriers increase, the result is a greater likelihood of unpreparedness. However, we did not find that level 2 (physical or developmental disabilities) or level 4 (extensive medical oversight) reported the same level of unpreparedness in the face of barriers. It is possible that households with individuals at level 2 and level 4 are more likely to receive aid from government institutions and local entities. For example, individuals with MSN level 2 (mental retardation, amputations, and blindness) have access to some services provided through the State Department of Health and Human Services. For individuals with level 4 MSN (requiring extensive medical oversight in the home), some level of access to services has already been obtained by these households and it is possible that preparedness plans are part of that medical oversight care. Further exploration of the interactions between barriers and MSN is needed not only in this Gulf Coast region where preparedness for hurricanes is essential but also in other geographic regions of the country and world where individuals with MSN may be at greater risk for morbidity or mortality in the face of a disaster.

We found that Hispanics were generally less likely to be unprepared for a hurricane than the non-Hispanic population in the region. Over $50 \%$ of the sample preferred Spanish language. Past research has found that primary Spanish-speaking Hispanics are more likely to report having an emergency evacuation plan although less likely to have the supplies necessary to survive during a disaster (11). Households with at least one person aged 65 years or older, and with less cash on hand were less likely to be unprepared for a hurricane. These results may indicate that individuals in those particular households have developed the networks and support needed to manage and create a sense of preparedness for hurricanes. We also found that as respondents' age increases in smaller households, the respondents indicated less unpreparedness. It is also possible that households with older individuals have faced and survived past hurricanes and therefore have a more accurate depiction of their preparedness for a hurricane. Finally, our results indicate that respondents living in households further from the shoreline indicated greater levels of unpreparedness. It is likely that this is a function of the belief that inland locations are safer from hurricane devastation than shoreline locations, and while not always an accurate belief could be an explanation of this finding.

Our study has limitations. One is that the surveys were based on interview and self-reported data and therefore potentially introduced respondent bias. The cross-sectional study design also limits any causation inferences. This study is based on a specific

\section{References}

1. Lee ACK, Challen K, Gardois P, Mackway-Jones K, Carley SD, Phillips W, et al. Emergency planning in health: scoping study of the international literature, local information resources and key stakeholders. NIHR Service Delivery and Organisation programme (2011).

2. United States. Congress. Senate. Committee on Health, Education, Labor, and Pensions. A Nation Prepared: Strengthening Medical and Public Preparedness and Response. Washington, DC: U.S. Government Publishing Office (2011). (S. HRG. 112-797). Available from: http://www.gpo.gov/fdsys/

3. Baker LR, Cormier LA. Disasters and Vulnerable Populations: Evidence-Based Practice for the Helping Professions. New York, NY: Springer Publishing Company (2014). geographical location with the sample comprised predominately of low income Hispanic households and thus may not be generalizable to other geographic regions or populations. Also, respondents answered evacuation barriers in response to hurricanes which are prominent in the area and may not be representative of barriers to a different natural disaster or emergency evacuation situation.

Future research should examine the role support systems have in preparedness for individuals with MSN. Not all individuals who need assistance or qualify for assisted living are housed in a facility. While we found that $33.2 \%$ of respondents in our study sample reported at least one individual with MSN (Level 0-4) in the household, we expect that this is a higher rate of MSN found in home settings because of high levels of poverty and lack of health insurance found in this region. Future research also should characterize the strategies and effectiveness of the public health system's response to the evacuation needs of the MSN population. This characterization could identify gold standard evacuation processes for MSN and foster their dissemination broadly.

\section{Conclusion}

Certain MSN populations in light of increasing barriers reported unpreparedness for hurricanes in a region of the country prone to such natural disasters. Our results characterize a population vulnerable to hurricanes, and highlight variables and interactions among variables influential in preparedness. This study contributes new understanding of preparedness among MSN populations.

\section{Authors Contributions}

LM, SC, and BR conceptualized the research hypothesis. KV conducted statistical analysis and LM, KV, SC, and BR interpreted the data. LM, KV, SC, and BR drafted the manuscript. All authors read and approved the final manuscript.

\section{Acknowledgments}

Work for the paper has been supported financially through the Texas Department of State Health Services (DSHS) \#2008-027641 and the UT Health Clinical and Translational Science Award (UL1 TR000371). We would also like to acknowledge Jason Palmer Callahan for his early contributions to the idea of examining medical special needs populations.

4. Fox MH, White GW, Rooney C, Rowland JL. Disaster preparedness and response for persons with mobility impairments results from the University of Kansas nobody left behind study. J Disabil Policy Stud (2007) 17:196-205. doi:10.1177/10442073070170040201

5. Nicholls N, Gruza G, Jouzel J, Karl T, Ogallo K, Parker D. Observed climate variability and change. In: Haughton J, editor. Climate Change 1995 The Science of Climate Change: Contribution of working group I to the second assessment report of the Intergovernmental Panel on Climate Change, Vol. 2. Cambridge: Cambridge University Press (1995). p. 133-92.

6. Balbus JM, Malina C. Identifying vulnerable subpopulations for climate change health effects in the United States. J Occup Environ Med (2009) 51:33-7. doi:10. 1097/JOM.0b013e318193e12e 
7. NCEMPR. Medical Special Needs Preparedness Symposium. Austin, TX: National Center for Emergency Medical Preparedness and Response (2009).

8. Texas Department of Public Safety. Evacuating the Special Needs Population. (2009). Available from: https://www.preparingtexas.org/Resources/documents/ TDEM\%20Training/G-364\%20toolkit/EvacuatingSpecialNeedsPopulation.pdf

9. Wakefield Research. The Adelphi Natural Disaster Survey: Emergency Preparedness Poll. Garden City, NY: Adelphi University (2012).

10. Bethel JW, Burke SC, Britt AF. Disparity in disaster preparedness between racial/ethnic groups. Disaster Health (2013) 1:110-6. doi:10.4161/dish.27085

11. Centers for Disease Control and Prevention. Household preparedness for public health emergencies - 14 states, 2006-2010. MMWR Morb Mortal Wkly Rep (2012) 61:713. doi:10.1001/jama.2012.13026

12. Reininger BM, Raja AS, Sanchez CA, Chen Z, Adams B, McCormick J, et al. Intention to comply with mandatory hurricane evacuation orders among persons living along a coastal area. Disaster Med Public Health Prep (2013) 7:46-54. doi:10.1001/dmp.2012.57

13. Reininger BM, Rahbar MH, Lee M, Chen Z, Alam SR, Pope J, et al. Social capital and disaster preparedness among low income Mexican Americans in a disaster prone area. Soc Sci Med (2013) 83:50-60. doi:10.1016/j.socscimed.2013. 01.037

14. Murphy ST, Cody M, Frank LB, Glik D, Ang A. Predictors of emergency preparedness and compliance. Disaster Med Public Health Prep (2009) 3:1-10. doi:10.1097/DMP.0b013e3181a9c6c5

15. Morrow BH. Identifying and mapping community vulnerability. Disasters (1999) 23:1-18. doi:10.1111/1467-7717.00102

16. National Organization on Disability. Report on Special Needs Assessment for Katrina Evacuees (SNAKE) Project (2005).

17. Riscoe P, Schlegelmilch J, Paturas J. Evacuation and Sheltering of People with Medical Dependencies-Knowledge Gaps and Barriers to National Preparedness (2013).

18. Gerber BJ, Norwood F, Zakour M. Disasters, evacuations and persons with disabilities: an assessment of key issues facing individuals and households. Evacuation Study for People with Disabilities, National Institute on Disability and Rehabilitation Research, United States Department of Education (Vol. 28), Washington, DC (2010). Available from: http://www.ohsu.edu/ $\mathrm{xd} /$ research/centers-institutes/institute-on-development-and-disability/ public-health-programs/upload/NIDRR_Indiv_Finding_Report_Disaster Evacuations_FINAL_6-10.pdf
19. Bethel JW, Foreman AN, Burke SC. Disaster preparedness among medically vulnerable populations. Am J Prev Med (2011) 40:139-43. doi:10.1016/j. amepre.2010.10.020

20. Ko JY, Strine TW, Allweiss P. Chronic conditions and household preparedness for public health emergencies: behavioral risk factor surveillance system, 2006-2010. Prehosp Disaster Med (2014) 29:13-20. doi:10.1017/ S1049023X13009126

21. Lindell MK, Prater CS, Sanderson WG, Lee HM, Yang Z, Mohite A, et al. Texas Gulf Coast Residents' Expectations and Intentions Regarding Hurricane Evacuation. College Station, TX: Hazard Reduction \& Recovery Center, Texas A\&M University (2001).

22. Lindell MK, Prater CS, Hwang SN, Wu JY, Zhang Y, Center R. Local Population and Estimated Evacuation in Risk Areas of the Texas Gulf Coast. College Station, TX: Hazard Reduction \& Recovery Center, Texas A\&M University (2002).

23. Reininger B, McCormick J, Rahbar MH, Raja SA, Saldaña V, Bautista L. Medical special needs assessment of lower Rio Grande valley, 2008. Brownsville, TX: University of Texas School of Public Health Brownsville Regional Campus \& Texas Department of State Health Services Health Service Region (2008). Available from http://www.co.cameron.tx.us/health/docs/MSN_Assessment.pdf

24. Blendon RJ, Benson JM, DesRoches CM, Lyon-Daniel K, Mitchell EW, Pollard WE. The public's preparedness for hurricanes in four affected regions. Public Health Rep (2007) 122:167.

25. StataCorp. Stata Statistical Software (Version 13) [Computer Software]. College Station, TX: StataCorp LP (2013).

26. SAS. SAS (Version SAS 9.1.3) [Computer software]. Cary, NC: SAS Institute, Inc (2000).

Conflict of Interest Statement: The authors of this manuscript declare no conflict of interest. There have been no payments or services for the work of this manuscript. There is no financial relationships with any entities that may have influenced the work of this manuscript. There are no declarations for patent or copyright for work related to this manuscript.

Copyright (c) 2015 Meyer, Vatcheva, Castellanos and Reininger. This is an open-access article distributed under the terms of the Creative Commons Attribution License (CC $B Y)$. The use, distribution or reproduction in other forums is permitted, provided the original author(s) or licensor are credited and that the original publication in this journal is cited, in accordance with accepted academic practice. No use, distribution or reproduction is permitted which does not comply with these terms. 